\title{
RESEARCH
}

Open Access

\section{Dimethyl fumarate alleviates the nitroglycerin (NTG)-induced migraine in mice}

${\text { Giovanna Casili }{ }^{1 \dagger}, \text { Marika Lanza }}^{1 \dagger}$, Alessia Filippone ${ }^{1}$, Michela Campolo ${ }^{1}$, Irene Paterniti ${ }^{1}$, Salvatore Cuzzocrea ${ }^{1,2}$ and Emanuela Esposito ${ }^{1 *}$

\begin{abstract}
Background: Oxidative stress and inflammatory pathways are involved in migraine and endogenous antioxidant defense system has a role in the prevention of hyperalgesia in migraine. In this study, we aimed to evaluate the role of the most pharmacologically effective molecules among the fumaric acid esters (FAEs), dimethyl fumarate, nuclear factor E2-related factor 2/antioxidant response element (Nrf-2/ARE) pathway-mediated, in regulating the hypersensitivity in a mouse model of nitroglycerine (NTG)-induced migraine.
\end{abstract}

Methods: Mice were orally administered with DMF at the doses of 10, 30, and $100 \mathrm{mg} / \mathrm{kg}, 5 \mathrm{~min}$ after NTG intraperitoneal injections. We performed histological and molecular analysis on the whole brain and behavioral tests after $4 \mathrm{~h}$ by NTG-migraine induction. The expression of nuclear factor kappa-light-chain-enhancer of activated B cells (NF-kB) subunit p65, nuclear factor of kappa light polypeptide gene enhancer in B-cells inhibitor alpha (IKBa), inducible nitrite oxide synthase (iNOS), cyclooxygenase 2 (COX-2), Nrf-2, manganese superoxide dismutase (MnSOD), and heme-oxygenase-1 (HO-1) were detected by Western blot. Tail flick, hot plate, orofacial formalin, and photophobia tests were used to evaluate migraine-like pain and migraine-related light sensitivity.

Moreover, we evaluate Nrf-2-dependent mechanism by the in vitro stimulation of cells extracted by trigeminal ganglia with diethylenetriamine/nitric oxide (DETA/NO), a nitric oxide (NO) donor. The cells were pre-treated with DMF and an antagonist of Nrf-2, trigonelline (TR) $2 \mathrm{~h}$ before DETA/NO stimulation.

Results: DMF treatment notably reduced histological damage as showed by cresyl violet staining; also, regulating both NF-kB and Nrf-2 pathway, DMF treatment decreased the severity of inflammation and increased the protective antioxidant action. Moreover, the headache was significantly reduced. The protective effect of DMF treatment, via Nrf-2, was confirmed in in vitro studies, through inhibition of Nrf-2 by trigonelline. Cytotoxicity, iNOS, and MnSOD expression were evaluated.

Conclusion: These results provided the evidence that DMF, by Nrf-2 modulation, has a protective effect on central sensitization induced by NTG, suggesting a new insight into the potential application of DMF as novel candidates in drug development for migraine.

Keywords: Migraine, Dimethylfumarate, Nrf-2, NF-kb

\footnotetext{
* Correspondence: eesposito@unime.it

${ }^{+}$Casili Giovanna and Lanza Marika contributed equally to this work.

${ }^{1}$ Department of Chemical, Biological, Pharmaceutical and Environmental

Sciences, University of Messina, Viale Ferdinando Stagno D 'Alcontres, 31,

98166 Messina, Italy

Full list of author information is available at the end of the article
}

(c) The Author(s). 2020 Open Access This article is distributed under the terms of the Creative Commons Attribution 4.0 International License (http://creativecommons.org/licenses/by/4.0/), which permits unrestricted use, distribution, and reproduction in any medium, provided you give appropriate credit to the original author(s) and the source, provide a link to the Creative Commons license, and indicate if changes were made. The Creative Commons Public Domain Dedication waiver (http://creativecommons.org/publicdomain/zero/1.0/) applies to the data made available in this article, unless otherwise stated. 


\section{Introduction}

Migraine is the third most common disease worldwide, with a higher prevalence in females (17.5\%) than in males (8.9\%) [1]. Sex differences in migraine also extend to greater symptomology, higher rate of visual auras, higher headache-related disability, and greater healthcare resource utilization by females [2]. To date, the triggering cause of migraine is unknown, but it is known that various factors, such as genetics and environmental factors, are partially involved in the debut of migraine attacks [3]. Recommended medications for the acute treatment of migraine encompass sumatriptans, nonsteroidal anti-inflammatory drugs (NSAIDs), and analgesics; particularly, the counter analgesics and nonsteroidal anti-inflammatory drugs for acute mild migraine and specific prescription drugs (sumatriptans and ergot alkaloids) for acute severe migraine [4]. While it is true that sumatriptans have been the first successful mechanism-driven treatment in the field, recently, new targets involved in migraine pathogenesis have emerged and new drug classes have been studied for migraine attack therapy [5]. Recently, calcitonin gene-related peptide (CGRP) antagonists are occupying a position of redress in the treatment of migraine [6]; the discovery that the levels of the CGRP peptide increase during a migraine attack and the infusion of CGRP can provoke a migraine attack have provided evidence for the study and development of small molecule antagonists, designed to block CGRP receptor action by preventing binding of the CGRP peptide [7]. Encouraged by the efficacy of blocking CGRP for the treatment of migraine, monoclonal antibodies able to block either CGRP or its receptors were developed and tested in several preclinical modalities and the field has been very active, with now three antibodies drug approved $[8,9]$. The three new FDA-approved drugs are erenumab, fremanezumab, and galcanezumab [6]. Initial programs on the development CGRP antagonists were frustrated by liver toxicity but the current outlook is very promising with five small molecule antagonists in various stages of clinical trial. Designed to decrease the number of migraine attacks, the new class of migraine drugs is metabolized differently and has fewer adverse reactions observed in clinical trials, as well as fewer warnings and precautions, compared to other approved migraine therapeutics. In general, blocking CGRP in migraine patients is seemingly both efficient and well tolerated; however, the inhibition of CGRP may pose a risk in subjects with comorbidities such as cardiovascular diseases, besides the fact that long-term effects are still unknown and that are often accompanied by high prices [10].

Migraine sufferers still have no effective and widely applicable drug treatment methods, thus the developing of more effective and safe anti-migraine agents is still a pressing task. Further studies are needed to investigate the possibility of combining different drug classes to optimize the clinical response and the potential role of the novel drugs in medication-overuse headache [5].

Though migraine causes are not understood, it demonstrated that oxidative stress is a universal migraine trigger. High levels of oxidative stress are associated with a fourfold increase in migraine risk and a recent study found that nearly all documented migraine triggers are associated with oxidative stress [11]. Also, migraine is a result of the interaction between multiple genes with environmental factors and triggers. The discovery of genes involved in this disease may lead to new insights into the molecular pathways in the pathogenesis of migraine because the discussed polymorphisms may influence the phenotypic features of migraine patients [12, 13]. Particularly, oxidative stress has been implicated in various headache disorders because it arises an imbalance between the production of reactive oxygen species (ROS) and elimination by antioxidant defense mechanisms, consequently with endogenous ROS that can cause oxidative damage to DNA, lipids, and proteins [14].

The master regulator of cellular cytoprotective responses to oxidative stress is nuclear factor erythroid-2related factor-2 (Nrf-2) [15]. Dimethyl fumarate, DMF, the most pharmacologically effective molecule among the fumaric acid esters (FAEs) and an oral therapeutic agent for the treatment of relapsing-remitting multiple sclerosis (MS) patients [16], was discovered to impact the antioxidative stress cell machinery promoting the transcription of genes downstream to the activation of Nrf-2 [17]. In fact, it has been found that the Nrf-2/ARE pathway is the most important endogenous antioxidant defense system, and plays a critical role in regulating cellular oxidation, cell defense, and protection; moreover, increasing data points out the protective role of $\mathrm{Nrf} 2 /$ ARE pathway activation in the brain [18]. A recent study demonstrated that activation of the Nrf-2/ARE pathway inhibited the activation of trigemino vascular system (TGVS) and prevented the induction of hyperalgesia, however without specifying the underlying mechanisms of migraine [19].

Thus, the aim of this study was to investigate the role of DMF, as an activator of Nrf-2/ARE pathway, in nitroglycerin (NTG)-induced hyperalgesia and its underlying mechanisms. In fact, it has been demonstrated that NTG administration produces attacks phenotypically similar to spontaneous migraine attacks and sensitizes trigeminal and cortical structures that underlie migraine allodynia [20].

In this study, we used sumatriptan, as positive control; sumatriptan is part of triptan family that is selective agonist of serotonin 5-hydroxytryptamine serotonin (5HT) 1B/1D receptors. It represents a very successful acute 
migraine therapy with a well-developed scientific validation, especially in reverting the behavioral hypersensitivity following NTG injection [21, 22].

Based on this finding, we speculate to consider DMF as an effective and alternative therapeutic approach to treat migraine pathology, reducing the side effects associated to traditional migraine treatments.

\section{Materials and methods}

In vivo study

Animals

CD1 mice (male 25 to 30 g, Envigo, Italy) were used for the in vivo study and Wistar rats (male 200-250 g, Envigo, Italy) were used for the in vitro study. Mice and rats were housed five per cages (five per cage) and maintained under a 12:12 h light/dark cycle at $21 \pm 1{ }^{\circ} \mathrm{C}$ and $50 \pm 5 \%$ humidity. Standard laboratory diet and tap water were available ad libitum. The University of Messina Review Board for the care of animals approved the study. Animal care was in compliance with Italian regulations on protection of animals used for experimental and other scientific purposes (Ministerial Decree16192) as well as with the Council Regulation (EEC) (Official Journal of the European Union L 358/112/18/1986).

\section{Migraine induction and DMF administration}

NTG was prepared from a stock solution of $5.0 \mathrm{mg} / \mathrm{ml}$ nitroglycerin in $30 \%$ alcohol, $30 \%$ propylene glycol, and water (American Reagent). NTG was freshly diluted in $0.9 \%$ saline to a dose of $10 \mathrm{mg} / \mathrm{kg}$. The vehicle used in these experiments, for Sumatriptan and DMF-treated groups, was $0.9 \%$ saline. All injections were administered as a $10 \mathrm{mg} / \mathrm{kg}$ volume. Animals were treated orally with DMF at the dose of $30 \mathrm{mg} / \mathrm{kg}$ and $100 \mathrm{mg} / \mathrm{kg}, 5 \mathrm{~min}$ following NTG injection. Mice were sacrificed $4 \mathrm{~h}$ following NTG injection; the whole brain with rostral spinal cord was removed and then dissected in order to evaluate the following parameters: histology analysis and Western blot analysis.

In a separate set of experiments, a cohort of 20 animals from each group was observed after NTG injection, receiving DMF until the sacrifice, in order to evaluate the behavioral testing. Also, for pre-treatment groups, we used only ten animals for histological evaluation.

\section{Experimental groups}

Animals were divided into six groups:

1. Sham group: mice received saline;

2. Sham + DMF (100 mg/kg) group: mice received orally DMF at the dose of $100 \mathrm{mg} / \mathrm{kg}$;

3. NTG group: mice received NTG $(10 \mathrm{mg} / \mathrm{kg})$ intraperitoneally;
4. NTG + sumatriptan group: mice received sumatriptan orally $(600 \mu \mathrm{g} / \mathrm{kg}) 5 \mathrm{~min}$ after NTG $(10 \mathrm{mg} / \mathrm{kg})$ intraperitoneally;

5. $\mathrm{NTG}+\mathrm{DMF}(30 \mathrm{mg} / \mathrm{kg})$ pre-treatment group: mice received orally DMF at the dose of $30 \mathrm{mg} / \mathrm{kg} 2 \mathrm{~h}$ before NTG injection;

6. NTG + DMF $(100 \mathrm{mg} / \mathrm{kg})$ pre-treatment group: mice received orally DMF at the dose of $100 \mathrm{mg} / \mathrm{kg}$ 2 h before NTG injection;

7. NTG + DMF $(30 \mathrm{mg} / \mathrm{kg})$ post-treatment group: mice received orally DMF at the dose of $30 \mathrm{mg} / \mathrm{kg}$ 5 min after NTG injection;

8. NTG + DMF $(100 \mathrm{mg} / \mathrm{kg})$ post-treatment group: mice received orally DMF at the dose of $100 \mathrm{mg} / \mathrm{kg}$ 5 min after NTG injection.

The minimum number of mice for every technique was estimated with the statistical test "ANOVA: Fixed effect, omnibus one-way" with G-power software. This statistical test generated a sample size equal to $n=10$ mice for each technique.

The selection of DMF treatment was based on its bioavailability, specifically the time to peak concentration of monomethylfumarate (MMF) after DMF administration is 2-2.5 h, and its half-life is approximately $1 \mathrm{~h}$ [23]. DMF was administered in pre- and post-treatment conditions; the doses $(10,30$, and $100 \mathrm{mg} / \mathrm{kg})$ of DMF used in this study were based on previous in in vivo experiments on metabolic and neuroinflammation diseases, dose response, and time-course studies by our laboratory. The preventive effects of DMF in migraine attacks were evaluated treating mice $2 \mathrm{~h}$ before NTG injections on the basis of DMF pharmacokinetics [24]. For both pre- and post-treatments, the histological effects of DMF were investigated on all three doses, but we decided to continue analyzing only DMF 30 and $100 \mathrm{mg} / \mathrm{kg}$ because DMF $10 \mathrm{mg} / \mathrm{kg}$ did not demonstrate any improvement of migraine in both pre- or post-treatment conditions. Furthermore, we showed only histological data associated to DMF alone group because toxicity or any other effects in comparison to sham control animals were not observed. The dose of sumatriptan used was based on previous experiment [22].

To better understand if the vehicle of NTG (a stock solution of $5.0 \mathrm{mg} / \mathrm{ml}$ nitroglycerin in 30\% alcohol, 30\% propylene glycol and water) could alter the effect of the treatments administered (Sumatriptan and DMF), in another set of experiment, mice were treated with Sumatriptan and DMF $100 \mathrm{mg} / \mathrm{kg}$ using the vehicle of NTG as vehicle, as better described in Additional file 1 .

\section{Behavioral testing Tail flick test}

Warm- and cold-water tail flick tests were conducted to assess thermal allodynia. Water temperature was maintained 
at $46 \pm 0.1{ }^{\circ} \mathrm{C}$ using a hot plate or at $15 \pm 0.1{ }^{\circ} \mathrm{C}$ using crushed ice. For testing, each mice were gently wrapped in a terry cloth towel and its tail submerged $5 \mathrm{~cm}$. Latency to flick or curl the tail was recorded with a 40-s cut-off [25].

\section{Orofacial formalin test}

The formalin test was performed according to the method of Fu et al. [26]. The mice received a subcutaneous injection of $20 \mu \mathrm{L}$ of diluted formalin (as the formalin model group) or saline (as the control group) into the center of the right vibrissa pad. DMF $(40 \mu \mathrm{l}$ for 30 and $100 \mathrm{mg} / \mathrm{kg}$ ) was injected intraperitoneally $30 \mathrm{~min}$ before formalin injection (as the formalin + DMF groups). After injection, the animals were immediately placed back in the test box to be observed for $45 \mathrm{~min}$. Observation period was divided into 15 blocks of $3 \mathrm{~min}$, and the number of seconds the animal spent in ipsilateral face rubbing or grooming was measured during phase I (0-12 $\mathrm{min})$ and phase II (12-45 $\mathrm{min})$ of formalin-induced pain [27]. An investigator analyzed the behavior in a blinded fashion.

\section{Hot plate test}

The hot plate test was carried out to assess the effects of agents on the thermal nociceptive threshold. Mice were placed on $52.58{ }^{\circ} \mathrm{C}$ hot plate. The response latency to either a hind-paw lick or jump was recorded. In the absence of a response, the animals were removed from the hot plate at $60 \mathrm{~s}$ to avoid tissue injury, and a 60-s latency was assigned as the response. The latency time to pain reaction was measured at $30,60,90,120$, and $240 \mathrm{~min}$ post NTG-induction [28].

\section{Light/dark test}

An apparatus was made to create a light/dark box used to quantify the ICHD-3 criteria of photophobia and reduced activity associated with migraine. Clear lids of the black and center gray chambers were covered with heavy black construction paper (inside $\leq 5 \mathrm{~lx}$ ); the white chamber with clear lids served as the light portion (inside $\geq$ $635 \mathrm{~lx}$ ). On test day, mice were placed into the center chamber for a 1-min acclimation period after which the guillotine-style doors were opened to allow access to the entire apparatus. Time in the light chamber and total number of photobeam breaks during a 5 -min test session were recorded [29].

\section{Elevated plus maze test}

Anxiety is one of the common behavioral conditions in migraine, so anxiety deficits were evaluated using elevated plus maze (EPM) system, as previously described (Pellow et al. 1985). EPM consisting of two open arms and two enclosed arms, animals were placed on the centre of the maze facing an open arm and following measures scored: time spent in enclosed arms (s) and number of entrances into open arms.

\section{Tissue processing and histology}

Following $4 \mathrm{~h}$ NTG injection, animals were evaluated by an experienced histopathologist. Longitudinal sections of $7-\mu \mathrm{m}$ thickness were processed from the brainstem at the trigeminal nucleus spinal trigeminal nucleus $(\mathrm{SpV})$. Sections were then deparaffinized with xylene and then stained with cresyl violet. For cresyl violet staining, the slides were fixed as described by [30]. All sections were studied using an Axiovision Zeiss microscope (Milan, Italy). Histopathologic changes of the gray matter were scored on a five-point scale: 0 , no lesion observed; 1 , gray matter contained one to five eosinophilic neurons; 2 , gray matter contained five to ten eosinophilics neurons; 3 , gray matter contained more than ten eosinophilics neurons; 4, small infarction (less than one-third of the gray matter area); 5, large infarction (more than half of the gray matter area). The scores from all the sections of each brain were averaged to give a final score for individual mice. All the histological studies were performed in a blinded fashion [31].

\section{Western blot analysis}

Western blot analysis was performed on whole brain with rostral spinal cord tissues harvested $4 \mathrm{~h}$ after NTG injection. Cytosolic and nuclear extracts were prepared as described previously [32]. The expression of nuclear factor of kappa light polypeptide gene enhancer in B cells inhibitor alpha ( $\mathrm{I} \kappa \mathrm{B}-\alpha)$, inducible nitric oxide synthase (iNOS), cyclooxygenase 2 (COX-2), manganese superoxide dismutase (Mn-SOD), and heme-oxygenase 1 (HO-1) was quantified in cytosolic fraction. Nuclear factor kappalight-chain-enhancer of activated B cells (NF- $\mathrm{kB}$ ) and nuclear factor erythroid 2-related factor 2 (Nrf-2) expressions were quantified in nuclear fraction. The filters were probed with specific Abs: anti-NF-kB (1:500; Santa Cruz Biotechnology) or anti-Nrf-2 (1:500; Santa Cruz Biotechnology, SC-722) or IкB- $\alpha$ (1:500; Santa Cruz Biotechnology), anti-MnSOD (1:500; Millipore) or anti-HO-1 (1:500; Santa Cruz Biotechnology), anti-COX-2 (1:500; Cayman) or iNOS $(1: 500$, Santa Cruz) in $1 \times$ PBS, $5 \% \mathrm{w} / \mathrm{v}$ nonfat dried milk, $0.1 \%$ Tween- 20 at $4{ }^{\circ} \mathrm{C}$, overnight. To ascertain that blots were loaded with equal amounts of proteins, they were also incubated in the presence of the antibody against GAPDH (cytosolic fraction 1:500; Santa Cruz Biotechnology) or lamin A/C (nuclear fraction 1:500 SigmaAldrich Corp.) as described [31].

\section{In vitro study \\ Primary cell culture}

Neuronal and satellite cell cultures from trigeminal ganglia were prepared from 6- to 7-day-old Wistar rats. 
Briefly, both trigeminal ganglia were aseptically removed as previously described [33]. Cells were mechanically dissociated using a Pasteur pipette, plated on a $25 \mathrm{~cm}^{2}$ flask, and incubated for a week, during which the medium was replaced twice, until reaching almost complete confluence. At this time, cells were detached from the flask by a 5 -min $0.05 \%$ trypsin-EDTA (Biochrom) treatment at $37{ }^{\circ} \mathrm{C}$, resuspended in fresh complete culture medium, and plated: in preliminary experiments to assess cell viability, $3 \times 10^{4}$ cells were plated in a volume of $150 \mu \mathrm{l}$ in 96-well plates. Increasing concentrations of DMF $(1,10,30,50,100 \mu \mathrm{M})$ were used to determine the effective concentrations with minimal cytotoxicity. The DMF concentrations chosen were 1 , 10 , and $30 \mu \mathrm{M}$. In another set of experiments, $8 \times 10^{5}$ cells were plated for $24 \mathrm{~h}$, then cells were pre-treated for $2 \mathrm{~h}$ with 1,10 , and $30 \mu \mathrm{M}$ DMF (based on previous 4,5dimethylthiazol-2-yl-2,5-diphenyltetrazolium bromide colorimetric cell viability assay), following by addition of diethylenetriamine/nitric oxide (DETA/NO) (Sigma-Aldrich, St. Louis, $\mathrm{MO}$ ), a nitric oxide (NO) donor, at the final concentration of $100 \mu \mathrm{M}$ for $6 \mathrm{~h}$ [33]. The protective concentration chosen was $30 \mu \mathrm{M}$ DMF; 1 and $10 \mu \mathrm{M}$ DMF were not protective in DETA/NO damaged cells. In another group, cells were preincubated for $30 \mathrm{~min}$ with $1 \mu \mathrm{M}$ of trigonelline (TR), a Nrf-2 inhibitor, as previously described (55) before treatment with DMF $(30 \mu \mathrm{M})$ and the following stimulation with DETA/NO; $6 \mathrm{~h}$ later, cell lysates were prepared for Western blot analysis.

Cells were divided into four groups:

1. Control group (Ctr): extracted cells were cultured with normal medium;

2. Control + TR group: extracted cells were pretreated with $1 \mu \mathrm{M}$ TR for $30 \mathrm{~min}$;

3. DETA/NO group: extracted cells were treated with $100 \mu \mathrm{M}$ of DETA/NO;

4. DETA/NO + DMF $30 \mu \mathrm{M}$ group: extracted cells were treated with DMF $30 \mu \mathrm{M}$ for $2 \mathrm{~h}$ before addition of $100 \mu \mathrm{M}$ of DETA/NO;

5. DETA/NO + DMF + TR group: extracted cells were pre-treated with $1 \mu \mathrm{M}$ TR for $30 \mathrm{~min}$, treated with DMF $30 \mu \mathrm{M}$ for $2 \mathrm{~h}$ before addition of $100 \mu \mathrm{M}$ of DETA/NO for $6 \mathrm{~h}$.

The time and the concentration of the treatments were based on previous study [34].

\section{Western blot analysis for primary cell cultures}

Western blot analysis was performed as previously described [35]. The membrane was incubated overnight at $4{ }^{\circ} \mathrm{C}$ with anti-iNOS (1:500; Transduction Labs) and antiMn-SOD (1:500; Merck-Millipore). To ascertain that blots were loaded with equal amounts of protein lysate, they were also incubated with GAPDH antibody (1:500; Santa Cruz Biotechnology).

\section{Statistical analysis}

All data are expressed as the mean \pm SEM. Statistical analyses were performed using PRISM 5 version 5.0 (SPSS Inc., Chicago, IL, USA). Data at different time points were analyzed using a two-way analysis of variance (ANOVA) followed by Bonferroni post-hoc test. Other data were analyzed using one-way ANOVA followed by Bonferroni post-hoc test. $P$ value $<0.05$ was considered as statistically significant.

\section{Results}

Post-treatment with DMF restored the NTG-induced damage in trigeminal nucleus

The symptoms that appear before the onset of migraine are related to abnormal neuronal activity in cortical and brainstem structures; particularly, it is widely accepted that trigeminal sensory information can reach the hypothalamus via multisynaptic pathways through the brainstem [36]. Central processes of sensory afferents enter the brainstem via the trigeminal tract and pass caudally while giving off collaterals that terminate mainly in lamina $\mathrm{V}$ of the spinal trigeminal nucleus, modulating the perception of trigeminal pain [37]. Thus, to define the NTG-induced alterations of $\mathrm{Sp} 5 \mathrm{C}$ area, whole brain with the rostral cervical spinal cord sections were stained with cresyl violet, observing a significant neuronal damage in NTG-injured mice (Fig. 1c, see histological score Fig. 1g) respect to control and NTG + sumatriptan group (Fig. 1a, d, see histological analysis Fig. 1g). On the contrary, the post-treatment with DMF, mainly at the dose of $100 \mathrm{mg} / \mathrm{kg}$, significantly ameliorated the cyto architecture of Sp5C area, restoring a large number of trigeminal neurons (Fig. 1f, see histological score Fig. 1g). Furthermore, mice treated with DMF $100 \mathrm{mg} / \mathrm{kg}$ (Fig. 1b, see histological score Fig. 1g), without suffering the NTG-damage, did not manifest any protective effect in comparison to sham control animals and NTG + sumatriptan group (Fig. 1a, d, see histological score Fig. 1g).

\section{The protective effects of DMF to reduce NTG-induced hyperalgesia}

NTG-evoked hyperalgesia in mice has been developed as a model for sensory hypersensitivity associated with migraine [38]. The tail flick test is a thermal hyperalgesia test in which the tail of the animal is subjected to a heat source, removing spontaneously the tail ("tail flick") when the fell situation become uncomfortable. In this study, DMF treatment administered after NTG caused a 


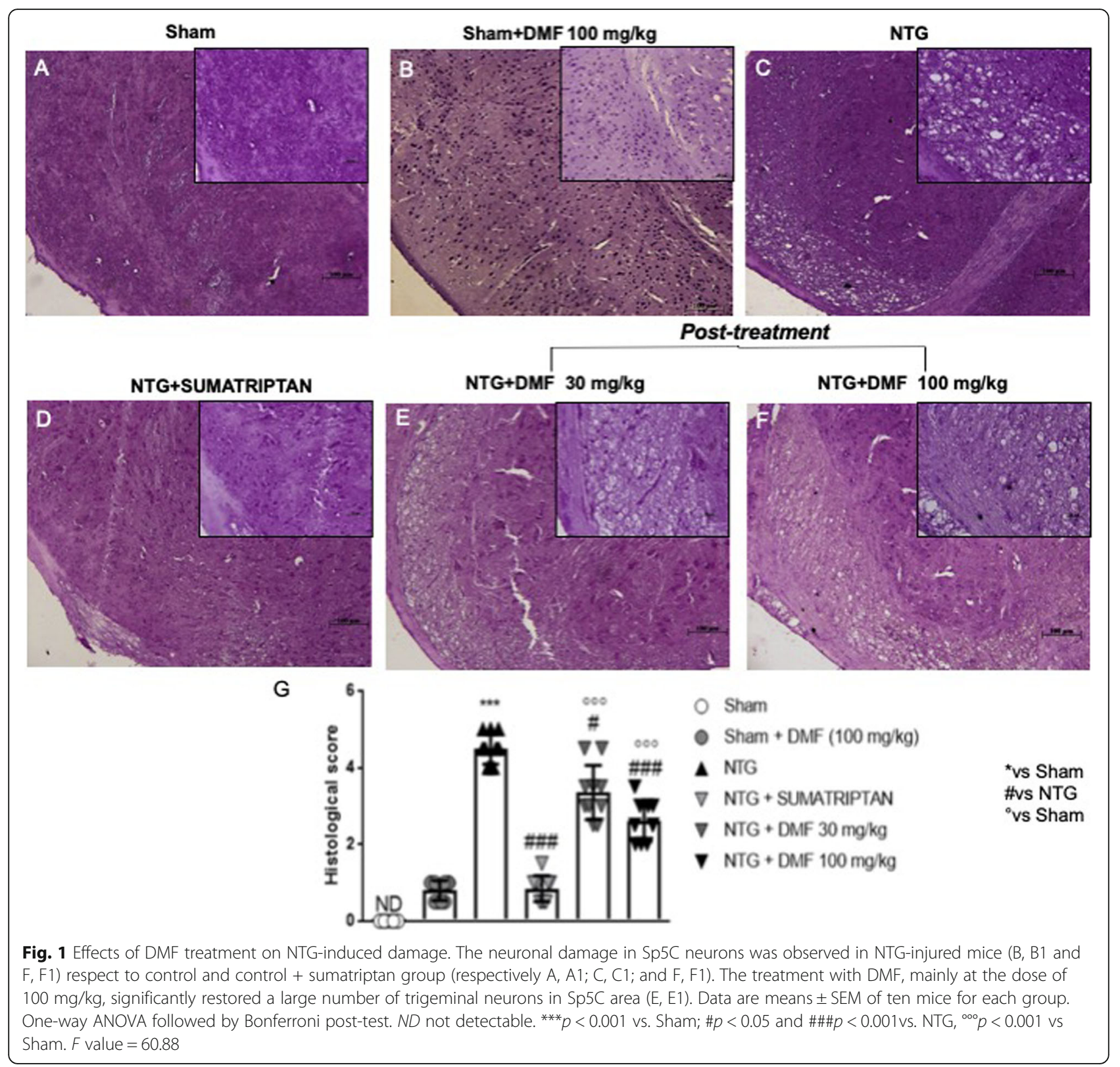

significant increase in tail flick latency, suggesting a DMF-mediated antinociceptive effect (Fig. 2a). Moreover, injection of NTG elicits thermal hypersensitivity in a time-dependent manner; thus, in this study, we evaluated the effect of DMF and Sumatriptan treatments on NTG-induced thermal hypersensitivity using the Hot plate test (Fig. 2b). The result highlighted that DMF treatment, at both doses of 30 and $100 \mathrm{mg} / \mathrm{kg}$, significantly increased the latency time to pain reaction related to the increase in time from 0 (starting time of NTG injection) up to $240 \mathrm{~min}$; furthermore, Sumatriptan treatment, as negative control, has increased even more the latency time to pain (Fig. 2b). In sham control and in sham + DMF-treated mice, the latency time to pain remained constant over time compared to a decrement observed in NTG-damaged mice starting from time 0 (Fig. 2b). Indeed, the pathophysiological mechanisms involved with migraine are suggestive of an increased and prolonged hyperexcitability to stimuli, especially within the trigeminal distribution. In the orofacial formalin test, total time spent in the face rubbing evoked by formalin injection was counted in phases 1 (Fig. 2c) and 2 (Fig. 2d) of the test. NTG administration significantly increased the total time of rubbing in phase II of formalin test, while DMF administration, at both doses of 30 and $100 \mathrm{mg} / \mathrm{kg}$, significantly reduced the nociceptive score (face-rubbing time) in both phases of the orofacial formalin test (Fig. 2c, d). 


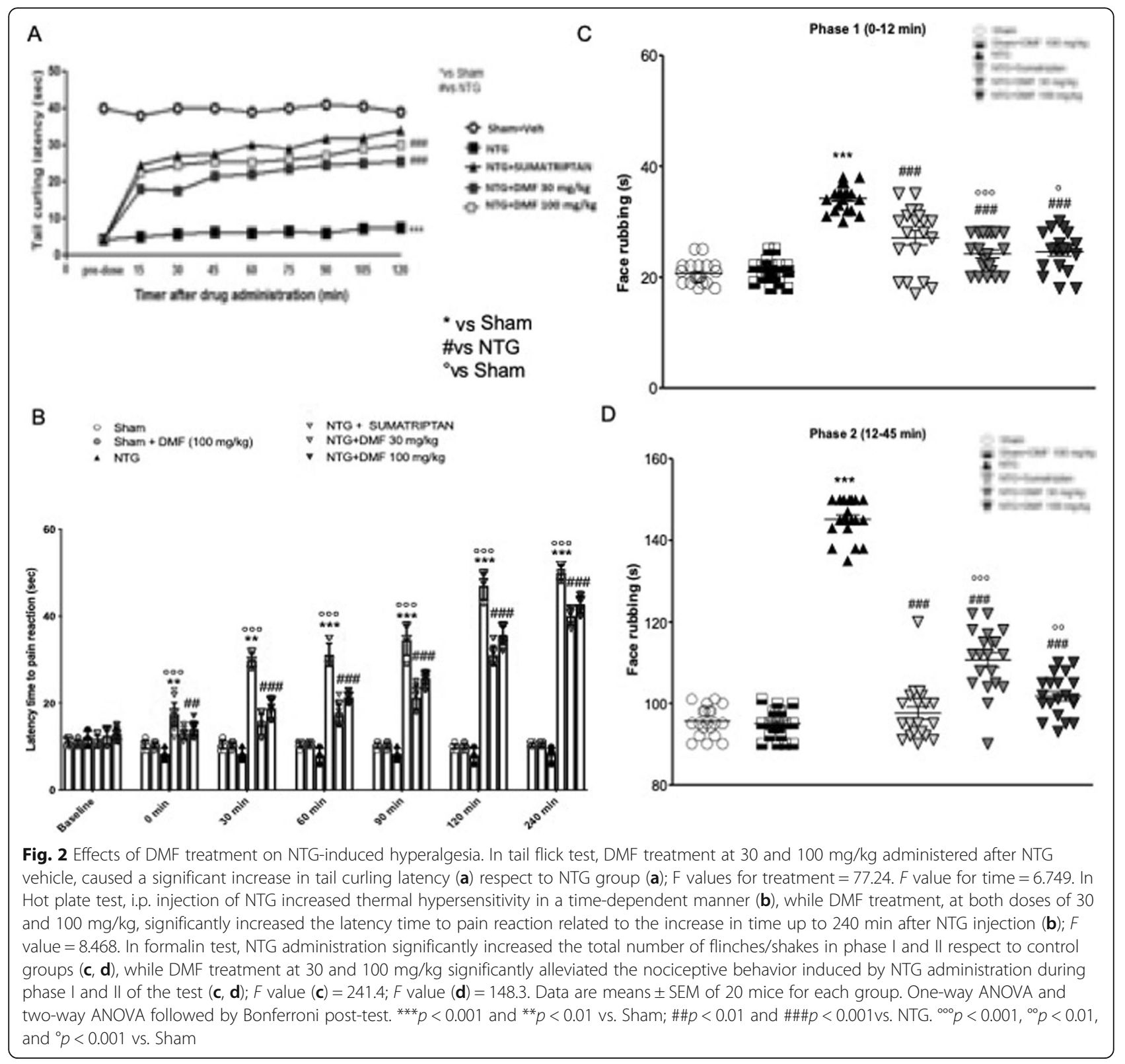

The role of DMF in the comorbidity between migraine and anxiety

Anxiety and mood disorders have been shown to be the most relevant psychiatric comorbidities associated with migraine, influencing disease prevalence and clinical outcomes [39]. Studies reported that mood and anxiety disorders are two to ten times more common in migraineurs than in the general population [40]. In this study, the time in closed arm and number of closed arm entries on the EPM test were used to evaluate anxiety. NTG-injected mice showed anxiety and fear to explore and they stationed in closed arm (Fig. 3a), while DMF-treated mice were encouraged and started to spend more time in open arm (Fig. 3a). In the same way, in migraine-affected mice, the number of entries in closed arm significantly increased (Fig. 3b) respect to control and sumatriptan groups (Fig. 3b); DMF treatment, mainly at $100 \mathrm{mg} / \mathrm{kg}$, reduced the number of entries in closed arm and augmented the permanence time in open arm (Fig. 3b). Indeed, a common and debilitating symptom often present in headache disorders is photophobia, related to pain caused by the trigeminal system alteration [41]. In this study, mice displaying migraine-like behaviors showed a strong tendency to stay longer in the dark zone respect to control mice and sumatriptan-treated mice (Fig. 3c). Conversely, NTGinjected mice, treated with DMF at both doses of 30 and $100 \mathrm{mg} / \mathrm{kg}$, started to leave the dark area and stayed more in the light zone (Fig. 3c). 


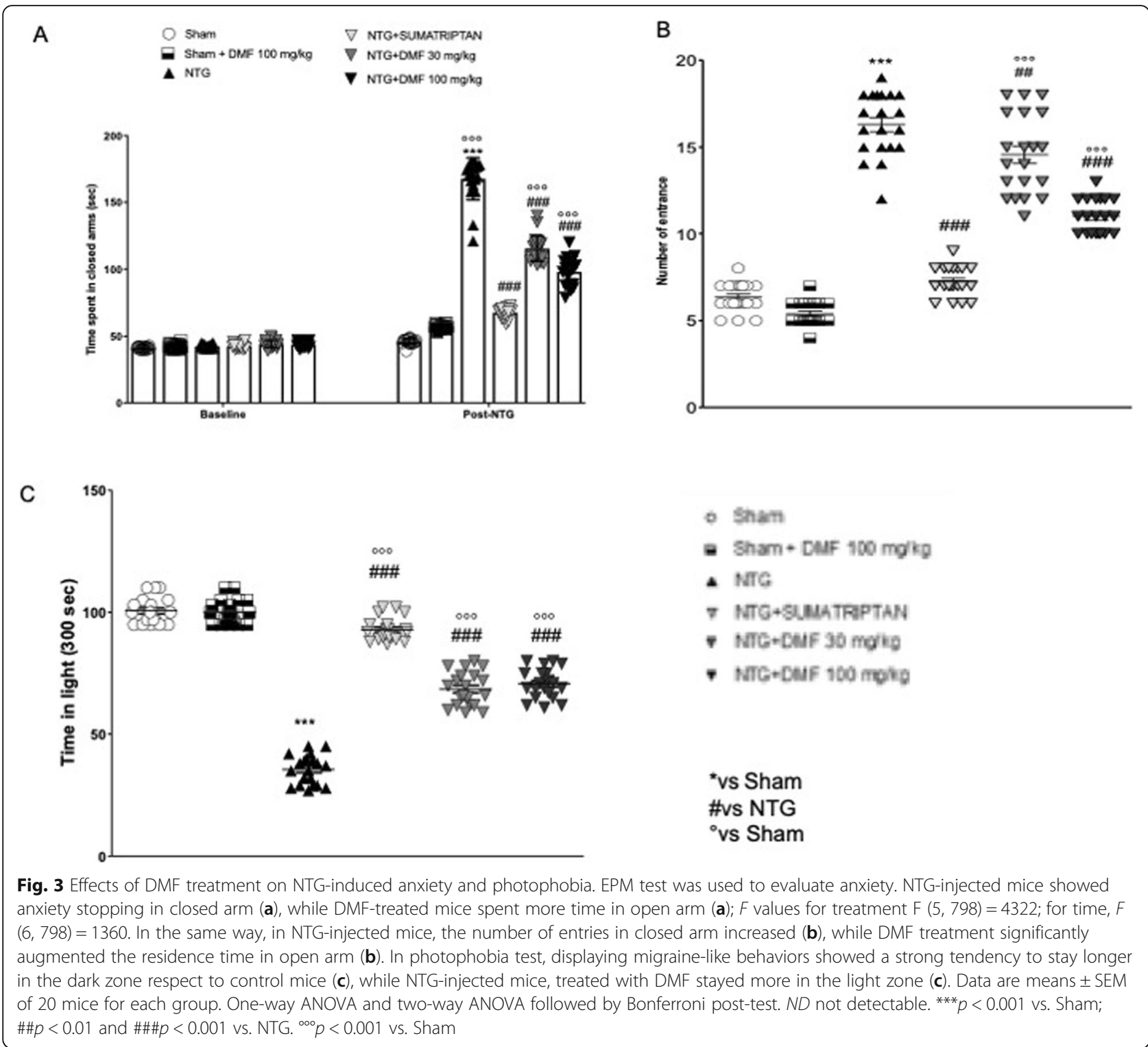

\section{The role of DMF on antioxidant system in NTG-induced migraine}

Oxidative stress is also believed to play a role in the pathogenesis of migraine [42]. Nrf-2 is a transcription factor with strong antioxidant effects, which protects neurons from ROS-induced damage. We evaluated the effects of DMF on Nrf-2 pathway and related proteins, in whole brain with the rostral cervical spinal cord samples, by Western blot analysis. Respectively, nuclear Nrf2 expression showed a tendency to increase following NTG-injection as compared to sham, sham + DMF and sumatriptan groups (Fig. 4(A), see densitometric analysis Fig. 4(A1)); DMF administration, at both doses of 30 and $100 \mathrm{mg} / \mathrm{kg}$, after migraine induction, up-regulated the activities of Nrf-2 (Fig. 4(A), see densitometric analysis Fig. 4(A1)). Moreover, DMF treatment, at both doses of 30 and $100 \mathrm{mg} / \mathrm{kg}$, after NTG injections, upregulated the activity of Mn-SOD (Fig. 4(B), see densitometric analysis Fig. 4(B1)), respect the basal expression in controls groups (Fig. 4(B), see densitometric analysis Fig. 4(B1)). Indeed, the levels of HO-1 were increased following NTG-damage compared to control and sumatriptan groups (Fig. 4(C), see densitometric analysis Fig. 4(C1)). Interestingly, treatment with DMF 30 and $100 \mathrm{mg} / \mathrm{kg}$ significantly upregulated, in the same way at both doses, HO-1 expression (Fig. 4(C), see densitometric analysis Fig. $4(\mathrm{C} 1))$. Furthermore, to assess whether the NTG-vehicle (30\% alcohol, 30\% propylene glycol, and water) could influence the antioxidant effects of DMF or Sumatriptan on control group, the expression of Nrf-2, Mn-SOD, and HO-1 was evaluate by Western blot analysis in whole brain with the rostral cervical 

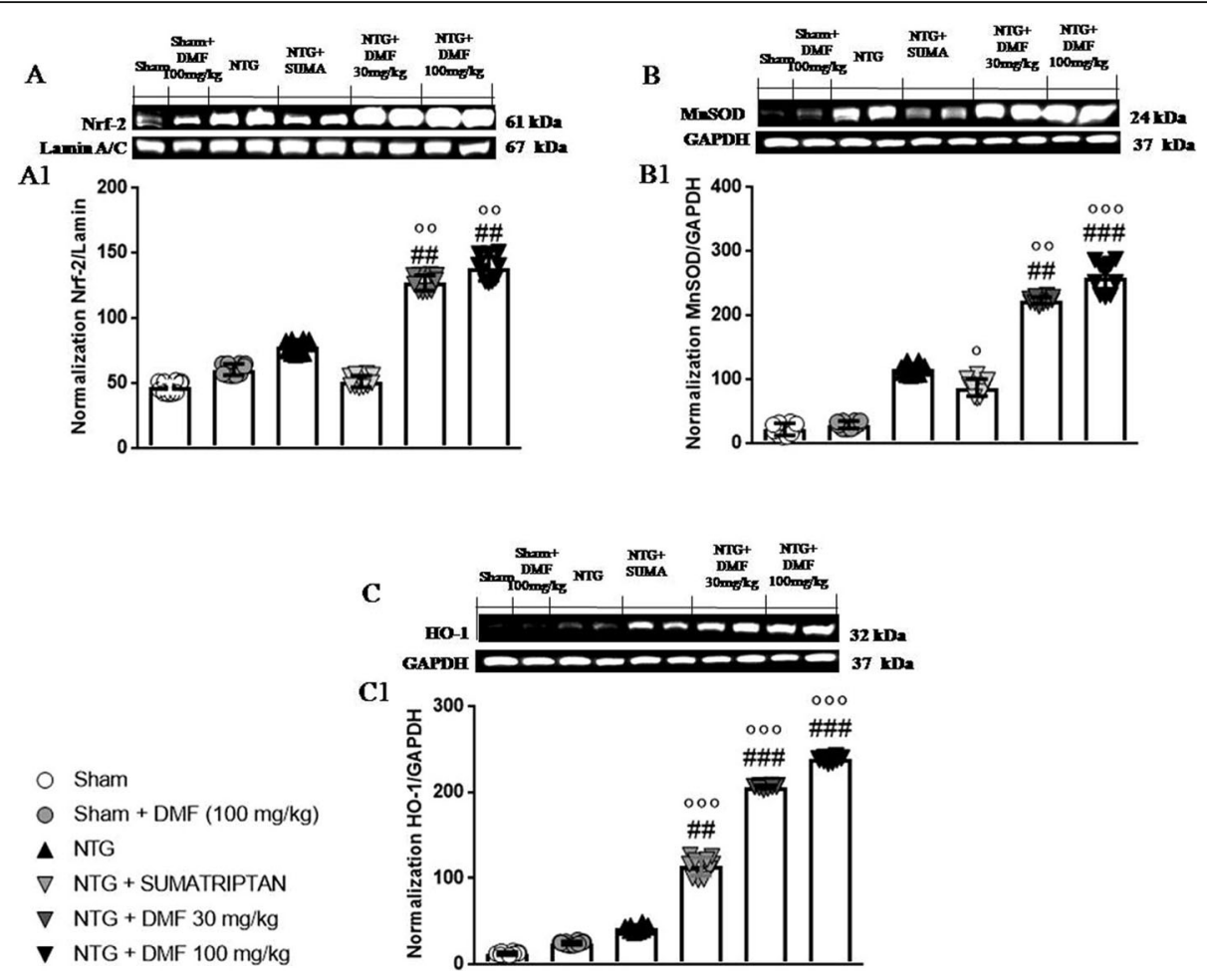

Fig. 4 Effects of DMF on antioxidant system in NTG-induced migraine. The expression of Nrf-2, Mn-SOD, and HO-1was observed by Western blot analysis in whole brain with the rostral cervical spinal cord samples of mice, $4 \mathrm{~h}$ after NTG-injections. Respectively, nuclear Nrf-2 expression increased following NTG-injection as compared to sham and sumatriptan groups (A), while DMF administration, at 30 and $100 \mathrm{mg} / \mathrm{kg}$, upregulated Nrf-2 activity (A); $F$ value $=438.9$. The same result was obtained for $\mathrm{Mn}-\mathrm{SOD}$ expression (B); $F$ value $=11.69$. The levels of HO-1 were notably increased following NTG-damage compared to control groups (C), while DMF treatment, at 30 and $100 \mathrm{mg} / \mathrm{kg}$, significantly up-regulated Mn-SOD and HO-1 expression $(B$ and $C) ; F$ value $=7.79$. Data are means \pm SEM of ten mice for each group. A representative blot of lysates obtained from each group is shown and densitometry analysis of all animals is reported ( $n=10$ mice from each group). One-way ANOVA followed by Bonferroni post-test. \#\#p $<0.01$ and \#\#\#p<0.01 vs. NTG; ${ }^{\circ} p<0.05,{ }^{\circ 0} p<0.01$ and ${ }^{000} p<0.001$ vs. Sham

spinal cord samples from NTG-vehicle-treated mice, as described in more details (see Additional file 1 and Additional file 2: Figure S2).

\section{The effects of DMF on NF-kB inflammatory pathway in NTG-induced migraine}

Oxidative stress-induced acute inflammatory responses may play an important role in the pathogenesis of acute pain arising from migraine [14]. To evaluate the antineuro inflammatory effect by which DMF treatment may regulate cytokines expression during headache attack, we assessed the expression of NF- $\kappa$ B, I $\mathrm{B}-\alpha$, iNOS, and COX-2 in whole brain with the rostral cervical spinal cord samples by Western blot analysis. We observed that NTG-injections caused a significant NF- $\mathrm{kB}$ nuclear translocation, almost completely inhibited by DMF 30 and $100 \mathrm{mg} / \mathrm{kg}$ treatments, as observed in Fig. 5(A and A1). Also, DMF treatment, only at the dose of $100 \mathrm{mg} /$ $\mathrm{kg}$, significantly reduced $\mathrm{I}_{\kappa} \mathrm{B}-\alpha$ cytosolic degradation respect to NTG-injected mice (Fig. 5(B), see densitometric analysis Fig. 5(B1)); still, the treatment with sumatriptan significantly reduced the cytosolic degradation of IKB- $\alpha$
(Fig. 5(B), see densitometric analysis Fig. 5(B1)). In sham and sham + DMF groups, the levels of IкB- $\alpha$ were significantly high respect to NTG group (Fig. 5(B), see densitometric analysis (Fig. 5(B1)). Indeed, a significant increase in iNOS expression was observed in the whole brain with the rostral cervical spinal cord samples from mice injected with NTG (Fig. 6(A), see densitometric analysis Fig. 6(A1)), while DMF treatment significantly reduced iNOS expression at 30 and $100 \mathrm{mg} / \mathrm{kg}$ (Fig. 6(A), see densitometric analysis Fig. 6(A1)) such as sumatriptan administration (Fig. 6(A), see densitometric analysis Fig. 6(A1)). COX-2 expression was significantly elevated in NTG-injected mice in comparison to control and sumatriptan groups (Fig. 6(B), see densitometric analysis Fig. 6(B1)). The rise in COX-2 expression induced by NTG was considerably blocked by treatment with DMF 30 and $100 \mathrm{mg} / \mathrm{kg}$ (Fig. 6(B), see densitometric analysis Fig. 6(B1)). Furthermore, to assess whether the NTGvehicle (30\% alcohol, 30\% propylene glycol, and water) could influence the anti-inflammatory effects of DMF or Sumatriptan on control group, the expression of NF-kB, IkB- $\alpha$, iNOS, and COX-2 was performed by Western 

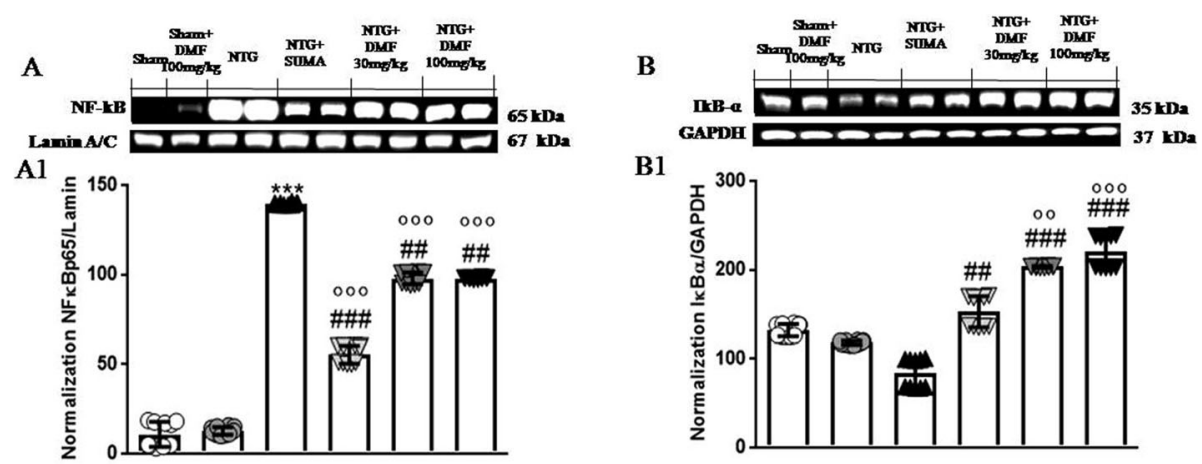

B1

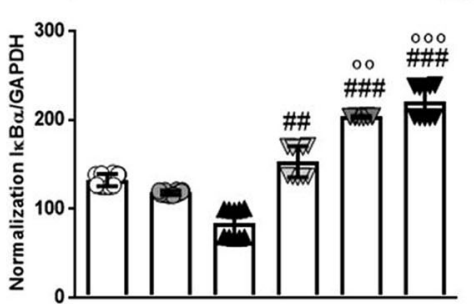

$$
\begin{array}{ll}
\text { O } & \text { Sham } \\
\text { O } & \text { Sham + DMF }(100 \mathrm{mg} / \mathrm{kg}) \\
\text { A } & \text { NTG } \\
\nabla & \text { NTG + SUMATRIPTAN } \\
\nabla & \text { NTG + DMF } 30 \mathrm{mg} / \mathrm{kg} \\
\nabla & \text { NTG + DMF } 100 \mathrm{mg} / \mathrm{kg}
\end{array}
$$

Fig. 5 Effects of DMF on NF-KB inflammatory pathway in NTG-induced migraine. The expression of NF-KB and IkB-a was observed by Western blot analysis, in whole brain with the rostral cervical spinal cord samples of mice, $4 \mathrm{~h}$ after NTG-injections. We observed that NTG-injections caused a significant NF-KB nuclear translocation, almost completely inhibited by DMF 30 and $100 \mathrm{mg} / \mathrm{kg}$ treatment (A); $F$ value $=165.6$. Also, DMF treatment, only at the dose of $100 \mathrm{mg} / \mathrm{kg}$, significantly reduced IKB-a cytosolic phosphorylation (B), while in NTG-injected mice the levels of IKB-a cytosolic phosphorylated were significantly increased respect to control groups (B); $F$ value $=166.2$. Data are means \pm SEM of ten mice for each group. A representative blot of lysates obtained from each group is shown and densitometry analysis of all animals is reported $(n=10$ mice from each group). One-way ANOVA followed by Bonferroni post-test. ${ }^{* *} p<0.001$ vs. Sham; \#\#p $<0.01$ and \#\#\#p $<0.001$ vs. NTG. One-way ANOVA followed by Bonferroni post-test. \#\#p 0.01 and \#\#\#p<0.01 vs. NTG; ${ }^{\circ} p<0.05,{ }^{\circ 0} p<0.01$, and ${ }^{000} p<0.001$ vs. Sham

blot analysis in whole brain with the rostral cervical spinal cord samples from NTG-vehicle-treated mice, as described in more details (see Additional file 1 and Additional file 2: Figure S2).

\section{Evaluation of Nrf-2-dependent mechanism of DMF in vitro} The preliminary step was to evaluate DMF effect on cell viability; neurons and satellite cell extracted from trigeminal ganglia were incubated with increasing concentrations of DMF (1-10-30-50-100 $\mu \mathrm{M})$. Cell viability assessed after $24 \mathrm{~h}$ showed that only DMF concentrations of 1,10 , and $30 \mu \mathrm{M}$ lacked cytotoxicity (Fig. 7(A)). The stimulation of cells with $100 \mu \mathrm{M}$ of DETA/NO significantly reduced viability, whereas pre-treatment with $30 \mu \mathrm{M}$ DMF, $2 \mathrm{~h}$ before DETA/NO, significantly reduced cell death compared with the DETA/NO group and the other concentrations (Fig. 7(B)), thus demonstrating that DMF at $30 \mu \mathrm{M}$ represented the most effective concentration. To confirm Nrf-2-dependent mechanism of DMF, cells from trigeminal ganglia were stimulated with the Nrf-2 antagonist TR $(1 \mu \mathrm{M}), 30 \mathrm{~min}$ before DMF treatment and the stimulation with DETA/ NO. TR notably inhibited the DMF cytoprotective effect compared with the DETA/NO when cells are pre- treated before damage (Fig. $7(\mathrm{C})$ ), while in cells treated only with TR, without DETA/NO damage, cell viability was similar to control (Fig. 7(C)). Moreover, to confirm the Nrf-2-mediated mechanism, to counteract inflammation and oxidative stress, we evaluated the expression of iNOS and Mn-SOD in trigeminal extracted cells. Western blot analysis demonstrated that iNOS expression was significantly increased in DETA/NO group compared with the control and TR alone group, while the pre-treatment with $30 \mu \mathrm{M}$ DMF decreased iNOS expression (Fig. 7(D), see densitometric analysis D1). However, TR abolished DMF protective effect against DETA/NO. In the same way, the incubation with $1 \mu \mathrm{M}$ of TR increased cells susceptibility to DETA/NO damage, lowering $\mathrm{Mn}$-SOD expression (Fig. 7(E), see densitometric analysis E1). Instead, cells treated with TR, without DETA/NO damage, expressed MnSOD levels similar to control group (Fig. 7(E), see densitometric analysis E1).

\section{The effects of pre-treatment with DMF in NTG-induced damage}

To better understand if DMF treatment could prevent damage caused by NTG, mice were pre-treated with DMF 2 h before NTG injections (Fig. 8). Pre-treatment 


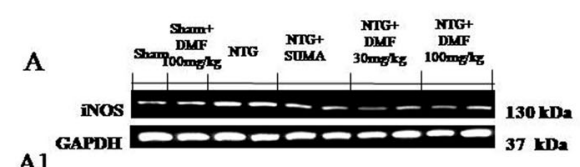

Al

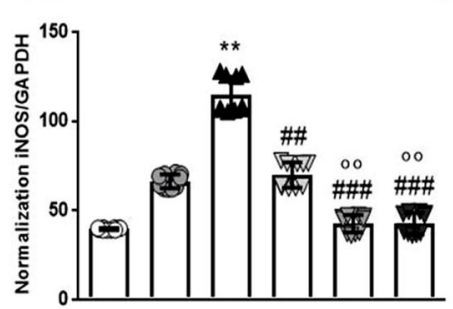

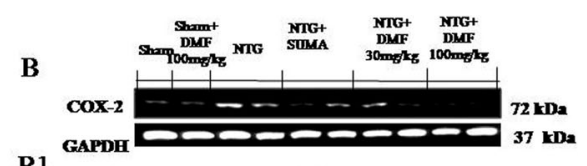

B1

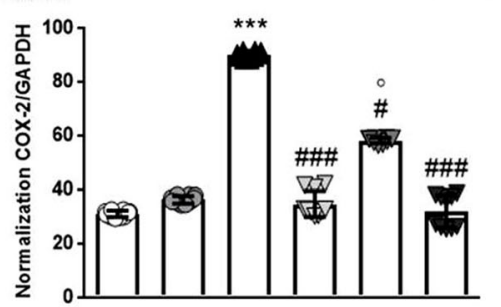

\footnotetext{
O Sham

O Sham + DMF (100 mg/kg)

A NTG

$\nabla$ NTG + SUMATRIPTAN

$\nabla \mathrm{NTG}+\mathrm{DMF} 30 \mathrm{mg} / \mathrm{kg}$

v $\mathrm{NTG}+\mathrm{DMF} 100 \mathrm{mg} / \mathrm{kg}$
}

Fig. 6 Effects of DMF on iNOS and COX-2 expression in NTG-induced migraine. The expression of iNOS and COX-2 was observed by Western blot analysis, in whole brain with the rostral cervical spinal cord samples of mice, $4 \mathrm{~h}$ after NTG-injections. A significant increase in iNOS expression was observed in NTG group (A), while DMF treatment significantly reduced iNOS expression at 30 and $100 \mathrm{mg} / \mathrm{kg}(\mathrm{A})$; $F$ value $=18.92$. Alike, COX2 expression was significantly elevated in NTG-injected mice in comparison to controls (B). The rise in COX-2 expression induced by NTG was considerably blocked by treatment with DMF 30 and $100 \mathrm{mg} / \mathrm{kg}(\mathrm{B})$; F value $=37.47$. Data are means \pm SEM of ten mice for each group. A representative blot of lysates obtained from each group is shown and densitometry analysis of all animals is reported $(n=10$ mice from each group). One-way ANOVA followed by Bonferroni post-test. ${ }^{* *} p<0.01$ and ${ }^{* * *} p<0.001$ vs. Sham; \#p $<0.05$, \#\#p $<0.01$, and \#\#\#p<0.001 vs. NTG; ${ }^{\circ} p<0.05$ and ${ }^{\circ} p<0.01$ vs. Sham

with DMF, at both doses of 30 and $100 \mathrm{mg} / \mathrm{kg}$, has not showed some preventive effects from the damage induced by NTG (Fig. 8d, e, see histological score Fig. 8f).

\section{Discussion}

Migraine represents one of the most disabling disorders [43]; therefore, medical approach should be individualized for adequate treatment of the migraine and other vascular risk factors. Several studies have shown that oxidative stress plays a role in central sensitization [44]. There are many factors that lead to the generation of oxidants in migraine; these could be explained by the metabolic changes in the cerebral cortex associated with intracellular calcium overload during cortical spreading depression (CSD) that bring to an increasing oxygen necessity which could induce oxidative stress [45, 46]. Local changes of cerebral blood flow may enhance the generation and release of free radicals, thus causing increased accumulation of lipid peroxidation by-products in blood [47, 48]. However, there are some conflicting data on the significance of oxidative stress in migraine $[49,50]$. The activity of antioxidant defense system is difficult to explain; therefore, a depth study may provide the desired information on the role of oxidative stress in migraine.

It has been found that Nrf2/ARE pathway is the most important endogenous antioxidant defense system and plays a critical role in regulating cellular oxidation, cell defense and protection [51]; moreover, Nrf-2 signaling cascade modulates both inflammation and oxidative stress. There are many drugs, already used clinically, that activate Nrf-2 system, including fumaric acid ester DMF [52]. DMF is an orally administered fumarate ester, approved as first-line monotherapy in early stage of MS [53]. Because DMF is rapidly and completely hydrolyzed by esterase, before reaching the systemic circulation, the pharmacologic activity of DMF is due to its active metabolite, monomethyl fumarate (MMF). Although nowadays the precise mechanism of action of DMF is not completely characterized, is thought to exert neuroprotective effects by activating Nrf-2 transcriptional pathway [18]. DMF was discovered to impact the antioxidative stress cell machinery promoting the transcription of genes downstream to the activation of Nrf-2, which besides immune regulatory effects [17].

Recently, studies demonstrated that DMF is highly active to counteract oxidative stress and inflammation by 


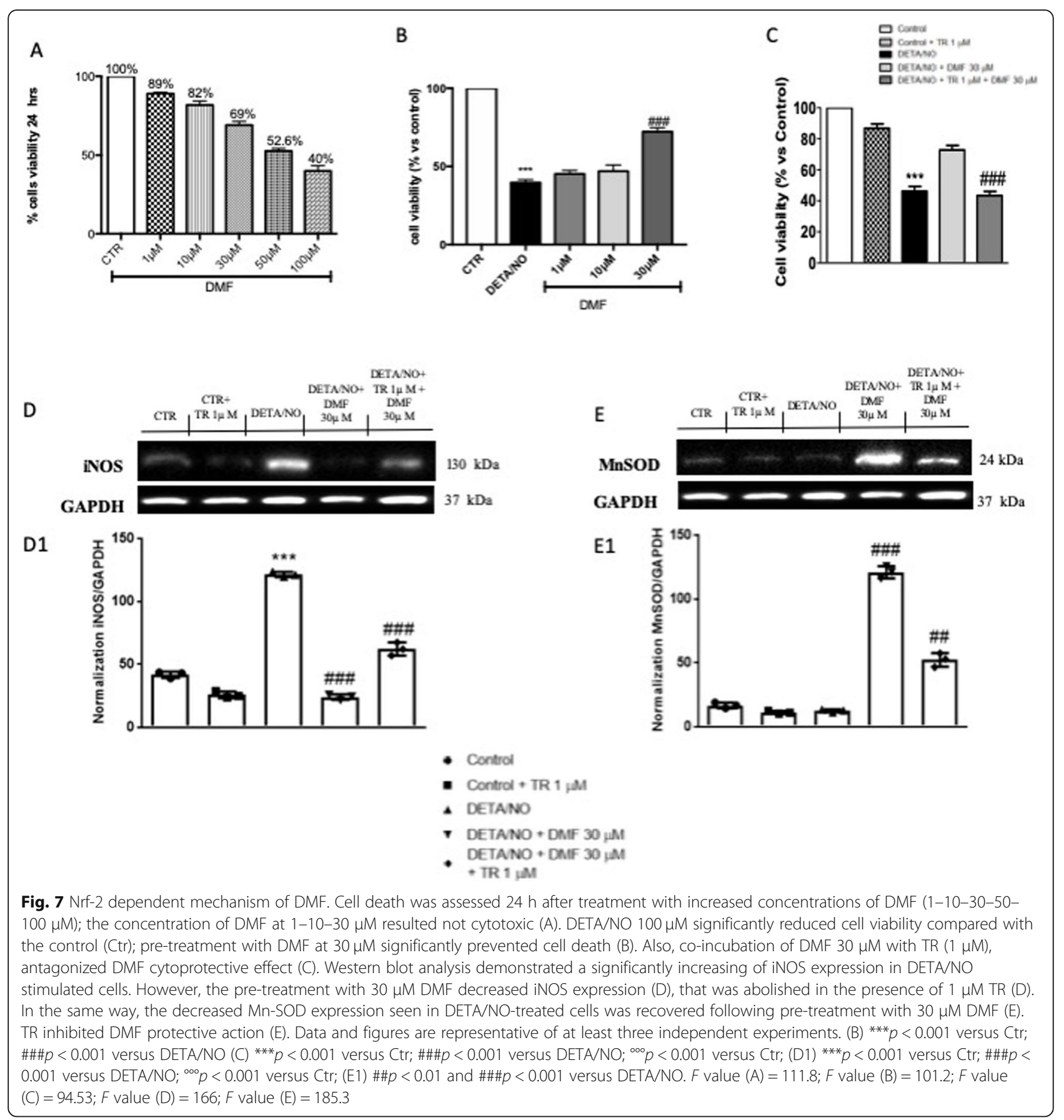

activating the Nrf-2 genetic program to promote axonal regeneration and neurological recovery in MS as well as in other neurodegenerative diseases [54], demonstrating that DMF can alleviate early brain injury and secondary cognitive deficits in experimental subarachnoid hemorrhage [55].

Moreover, the role of Nrf-2 pathway was recently observed in in vivo model of headache demonstrating that the modulation of the Nrf2/ARE pathway inhibited the activation of trigeminus vascular system (TGVS) and prevented the induction of hyperalgesia [19]. In support of this finding, we investigated the neuroprotective effect of DMF in NTG-induced hyperalgesia through the modulation of Nrf2/ARE pathway and its underlying mechanism.

The effect of DMF on analgesia was observed by the hot plate test, tail flick, and orofacial formalin test, which are standard behavioral models for the assessment of analgesia [56]. Our result showed the analgesic role of DMF thought a significant reduction of mechanical allodynia caused by NTG administrations, relieving stimulus- 

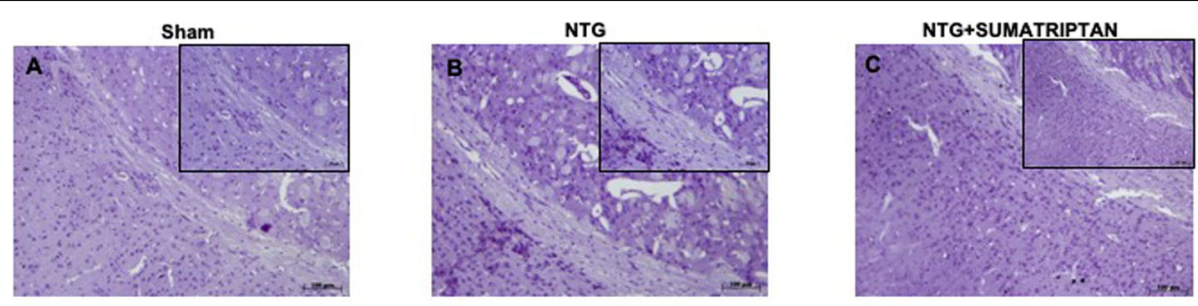

Pre-treatment

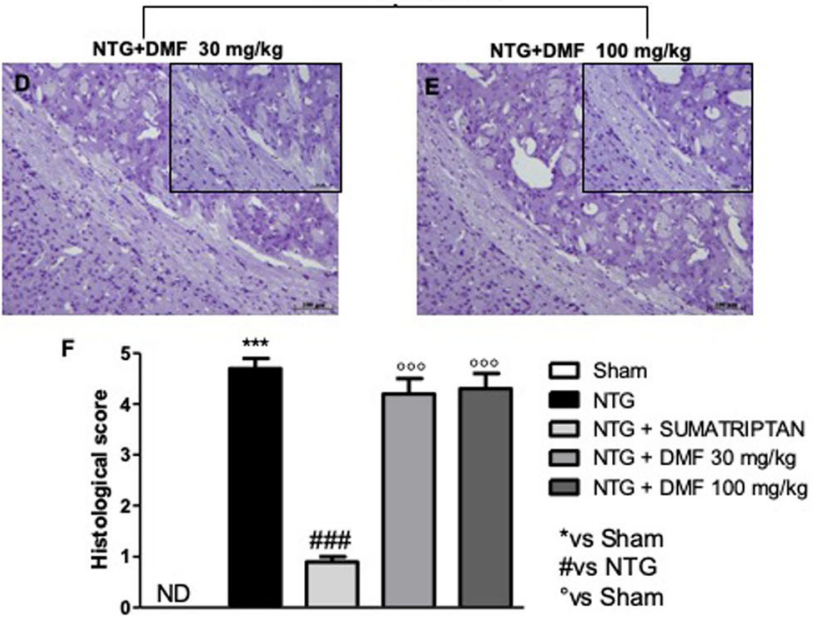

Fig. 8 Effects of DMF pre-treatment on NTG-induced damage. The neuronal damage in Sp5C neurons was observed in NTG-injured mice (B, B1 and $F, F 1)$ respect to control (A, A1 and F, F1). The pre-treatment with DMF did not restored damage in trigeminal Sp5C area $(D, D 1 ; E, E 1$ and F, F1). Data are means \pm SEM of ten mice for each group. One-way ANOVA followed by Bonferroni post-test. ND not detectable. ${ }^{* * *} p<0.001$ vs. Sham; \#\#\#p $<0.001$ vs. NTG, ${ }^{\circ 00} p<0.001$ vs. Sham. F value $=104.7$

evoked spontaneous nociception. Moreover, in acute and chronic hyperalgesia conditions, DMF was able to counteract peripherally pain, as evaluated by the reduction of total time of rubbing in orofacial formalin test.

The primary headache, particularly migraine, has a bidirectional relationship with depression and anxiety. Patients with depression have a more than threefold relative risk of developing migraine compared with nondepressed patients. Similarly, migraineurs have a more than threefold relative risk of developing depression compared with patients without migraine [57]. The EPM test, used in this study, quantified the anxiety-like behavior associated with repeated migraine attacks demonstrating the importance of DMF treatment to reduce the rates of anxiety and depression.

Furthermore, the perception of migraine headache is intensified during exposure to light [58]; in fact, the migraine photophobia is experienced by nearly $90 \%$ of migraineurs with normal eyesight, and depends on photic signals from the eye that converge on trigemino vascular neurons somewhere along its path. In this study, we showed that NTG injection caused light aversion in mice that was attenuated by DMF treatment, in a dose-dependent manner.

The most common migraine-associated symptoms (nausea, throbbing pain, photophobia) originate from activation of nociceptors innervating pial, arachnoid and dural blood vessels. Central processes of meningeal sensory afferents enter the brainstem via the trigeminal tract and pass caudally while giving off collaterals that terminate in the spinal trigeminal nucleus (Sp5C) and upper cervical spinal cord. Anatomical and electrophysiological studies have shown that the nociceptive innervation consists of unmyelinated (C-fibers) and thinly myelinated (A $\delta$ fibers) axons containing vasoactive neuropeptides such as substance $\mathrm{P}(\mathrm{SP})$ and calcitonin generelated peptide (CGRP), that originate in the trigeminal ganglion [59]. Preclinical data suggested that primary headaches are initiated by the activation of meningeal perivascular nociceptors that in turn activate brainstem trigeminovascular (Sp5C) neurons [60]. A large number of endogenous inflammatory mediators, believed to be released during migraine, are capable of activating and sensitizing peripheral and central $\mathrm{Sp} 5 \mathrm{C}$ neurons, particularly the sensitization of second-order neurons in the $\mathrm{Sp} 5 \mathrm{C}$ mediates cephalic allodynia as well as muscle tenderness [61]. These meningeal nociceptors converge on trigemino vascular $\mathrm{Sp} 5 \mathrm{C}$ neurons that receive additional input from the adjacent skin and muscles [62, 63]. In this study, we observed that DMF significantly reduced the $\mathrm{Sp} 5 \mathrm{C}$ degeneration induced by NTG-administration, resulting in a reduction in referred pain perception 
caused by the resultant convergence of intracranial (visceral) and extracranial (somatic) primary afferents onto Sp5C neurons.

Central sensitization associated with activation of NF$\kappa \mathrm{B}$ in the trigeminal cervical complex (TNC) is reported to be involved in the pathogenesis of migraine [19]. NF$\kappa \mathrm{B}$ is believed to be implicated in multiple signaling pathways in variable headache settings and, particularly, $\mathrm{Li}$ et al. showed that the impairments due to NTGinduced migraine are caused by the activation of NF- $\mathrm{KB}$ signal transduction pathway [64]. Also, the activation of NF- $\mathrm{kB}$ transcriptional activity in brain nuclei that are relevant for pain transmission observed in an animal model of migraine suggested a potential new avenue for the development of anti-migraine drugs [65]. In the past, it was demonstrated that targeting the inflammatory response by selectively inhibiting NF- $\mathrm{kB}$ offered a promising therapeutic approach for the treatment of headache [66]. Recently, in a study on the upregulation of inflammatory gene transcripts in chronic migraineurs, it has been discovered that three of the four genes that are abnormally expressed in chronic migraine patients-the NF-kBIA, the TNFAIP3, and the ILR2-are tightly related to the NF- $\kappa B$ family pathway, suggesting that suppression of NF- $\mathrm{kB}$ activation is critical in resolving the inflammation and consequently in reducing the pain involved in the pathophysiology of the studied chronic migraine patients [67]. Collectively, the findings point to a dual mechanism in headache: the first is activation of proinflammatory pathways and the second is suppression of pathways involved in resolving the inflammation. Particularly, in headache, neurogenic inflammation is responsible of the characteristic symptoms as pain and sensitization, because mast cells that reside close to primary nociceptive neurons are capable of triggering local inflammation [68].

Recently, it has been demonstrated that DMF induced Nrf-2 expression suppresses the NF- $k B$ mediated inflammatory pathway [69]. Moreover, the identification of NF- $\mathrm{kB}$ binding cites in the promoter region of the Nrf-2 gene suggests cross talk between these two regulators of inflammatory processes [34] .

In this study, we demonstrated that DMF treatment inhibited the nuclear translocation of NF- $\mathrm{kB}$, representing a functional system to regulate neuroinflammation in response to migraine.

NF- $\mathrm{KB}$ activation is correlated with an upregulation of proinflammatory mediators such as tumor necrosis factor (TNF)- $\alpha$, interleukins, and prostaglandins as well as nitrosative stress. In this study, DMF treatment significantly reduced iNOS and COX-2 expressions.

In response to inflammatory and oxidative stimuli, upregulation of Nrf-2 signaling inhibits the overproduction of proinflammatory cytokines and chemokines as well as limiting the activation of NF- $\mathrm{KB}$ [70]. In normal conditions, Nrf-2 is located in the cytosol, under oxidative stressors Nrf2 translocate to the nucleus activating antioxidative genes [71]. In this study, we observed that NTG administration significantly increased nuclear Nrf-2 expression in mice as well as the expression Nrf-2-regulated phase II enzymes, Mn-SOD and HO-1 [72]. DMF treatments markedly upregulated the antioxidant enzymes, demonstrating its important role in the reduction of oxidative stress related to migraine. Moreover, our study clearly showed that DFM in a pre-treatment condition was unable to prevent NTG tissue damage, validating its use only as a post-treatment during migraine attack.

\section{Conclusion}

In this study, we demonstrated for the first time the DMF potential for treatment of migraine, modulating the inflammatory state and strengthening the antioxidant Nrf-2 transcriptional pathway, as confirmed by the in vitro study. Moreover, considering that anxiety plays an important fact in migraine risk, detecting anxiety symptoms and implementing pharmacological and not treatments targeting Nrf-2/NF- $\mathrm{BB}$ pathway could improve headache control and patient's quality of life. In conclusion, DMF could be considered as promising therapeutic approach in counteract the inflammation and oxidative stress associated to migraine.

\section{Supplementary information}

Supplementary information accompanies this paper at https://doi.org/10. 1186/s12974-020-01736-1.

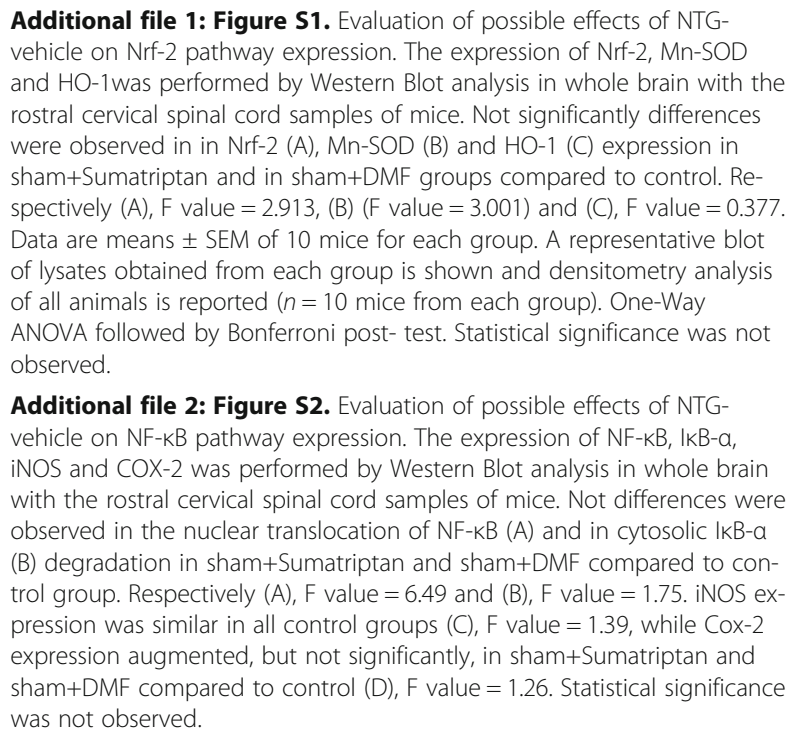
and $\mathrm{HO}-1$ was performed by Western Blot analysis in whole brain with the rostral cervical spinal cord samples of mice. Not significantly differences were observed in in Nrf-2 (A), Mn-SOD (B) and HO-1 (C) expression in sham+Sumatriptan and in sham+DMF groups compared to control. Respectively $(A), F$ value $=2.913$, $(B)(F$ value $=3.001)$ and $(C), F$ value $=0.377$ Data are means \pm SEM of 10 mice for each group. A representative blot of lysates obtained from each group is shown and densitometry analysis of all animals is reported ( $n=10$ mice from each group). One-Way ANOVA followed by Bonferroni post- test. Statistical significance was not observed.

Additional file 2: Figure S2. Evaluation of possible effects of NTGvehicle on NF-kB pathway expression. The expression of NF-kB, IKB-a, iNOS and COX-2 was performed by Western Blot analysis in whole brain with the rostral cervical spinal cord samples of mice. Not differences were observed in the nuclear translocation of NF-KB (A) and in cytosolic IKB-a (B) degradation in sham+Sumatriptan and sham+DMF compared to control group. Respectively (A), F value $=6.49$ and $(B), F$ value $=1.75$. iNOS expression was similar in all control groups (C), F value $=1.39$, while Cox-2 expression augmented, but not significantly, in sham+Sumatriptan and sham+DMF compared to control (D), F value $=1.26$. Statistical significance was not observed.

\section{Abbreviations}

5-HT: Serotonin 5-hydroxytryptamine serotonin; COX-2: Cyclooxygenase 2; DETA/NO: Diethylenetriamine/nitric oxide; DMF: Dimethylfumarate;

EPM: Elevated plus maze; FAE: Fumaric acid esters; GPCR: Calcitonin gene- 
related peptide; HO-1: Heme-oxygenase-1; INOS: Inducible nitrite oxide synthase; IkBa: Nuclear factor of kappa light polypeptide gene enhancer in B-cells inhibitor alpha; MMF: Monomethylfumarate; Mn-SOD: Manganese superoxide dismutase; MS: Multiple sclerosis; NF-kB: Nuclear factor kappalight-chain-enhancer of activated B cells subunit p65; NO: Nitric oxide; Nrf2: Nuclear factor erythroid-2-related factor-2; NSAID: Nonsteroidal antiinflammatory drugs; NTG: Nitroglycerin; ROS: Reactive oxygen species; SpV: Spinal trigeminal nucleus; TGVS: Trigemino vascular system

\section{Acknowledgments}

Michela Campolo is a researcher for PON "Ricerca e Innovazione" 2014/ 2020 - AIM "Attraction and International Mobility".

\section{Authors' contributions}

GC and ML drafted the manuscript, participated in research design, and carried out behavioral analysis; AF, MC, and IP carried out the in vivo and in vitro experiments and performed biochemical analysis; EE analyzed the data; SC analyzed the data and designed the preclinical experiments. All authors read and approved the final submitted version of the manuscript.

\section{Funding}

This research was supported by PRIN 2015N4FKJ4_004.

\section{Availability of data and materials}

The datasets used and/or analyzed during the current study are available from the corresponding author on reasonable request.

\section{Ethics approval and consent to participate}

Not applicable.

\section{Consent for publication}

Not applicable.

\section{Competing interests}

The authors declare that they have no competing interests.

\section{Author details}

'Department of Chemical, Biological, Pharmaceutical and Environmental Sciences, University of Messina, Viale Ferdinando Stagno D 'Alcontres, 31, 98166 Messina, Italy. ${ }^{2}$ Department of Pharmacological and Physiological Science, Saint Louis University, Room M 36-1402 South Grand Blvd, St. Louis, MO 63104, USA.

Received: 30 July 2019 Accepted: 5 February 2020

Published online: 17 February 2020

\section{References}

1. Agosti R. Migraine burden of disease: from the patient's experience to a socio-economic view. Headache. 2018;58(Suppl 1):17-32

2. Maleki N, Androulakis XM. Is there any MRI pattern that discriminates female from male migraine patients? Front Neurol. 2019:10:961.

3. Mulder E, Van Baal C, Gaist D, Kallela M, Kaprio J, Svensson DA, Nyholt DR, Martin

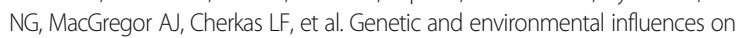
migraine: a twin study across six countries. Twin Res. 2003;6:422-31.

4. Reddy DS. The pathophysiological and pharmacological basis of current drug treatment of migraine headache. Expert Rev Clin Pharmacol. 2013;6:271-88.

5. Lupi C, Benemei S, Guerzoni S, Pellesi L, Negro A. Pharmacokinetics and pharmacodynamics of new acute treatments for migraine. Expert Opin Drug Metab Toxicol. 2019;15:189-98.

6. Rujan RM, Reynolds CA. Calcitonin gene-related peptide antagonists and therapeutic antibodies. Handb Exp Pharmacol. 2019;255:169-92.

7. Hay DL, Walker CS. CGRP and its receptors. Headache. 2017:57:625-36.

8. Edvinsson L. CGRP receptor antagonists and antibodies against CGRP and its receptor in migraine treatment. Br J Clin Pharmacol. 2015;80:193-9.

9. The Lancet N. Complicated decisions on new migraine-prevention therapies. Lancet Neurol. 2019;18:221.

10. Deen M, Correnti E, Kamm K, Kelderman T, Papetti L, Rubio-Beltran E, Vigneri S, Edvinsson L, Maassen Van Den Brink A, European Headache Federation School of Advanced S. Blocking CGRP in migraine patients-a review of pros and cons. J Headache Pain. 2017;18:96.
11. Borkum JM. Migraine triggers and oxidative stress: a narrative review and synthesis. Headache. 2016;56:12-35

12. de Vries B, Frants RR, Ferrari MD, van den Maagdenberg AM. Molecular genetics of migraine. Hum Genet. 2009;126:115-32.

13. Kowalska M, Prendecki M, Kozubski W, Lianeri M, Dorszewska J. Molecular factors in migraine. Oncotarget. 2016;7:50708-18.

14. Geyik S, Altunisik E, Neyal AM, Taysi S. Oxidative stress and DNA damage in patients with migraine. J Headache Pain. 2016;17:10

15. Belcher JD, Chen $C$, Nguyen J, Zhang P, Abdulla F, Nguyen $P$, Killeen $T, X u$ P, O'Sullivan G, Nath KA, Vercellotti GM. Control of oxidative stress and inflammation in sickle cell disease with the Nrf2 activator dimethyl Fumarate. Antioxid Redox Signal. 2017;26:748-62.

16. Kappos L, Gold R, Miller DH, Macmanus DG, Havrdova E, Limmroth V, Polman $\mathrm{CH}$, Schmierer $\mathrm{K}$, Yousry TA, Yang M, et al. Efficacy and safety of oral fumarate in patients with relapsing-remitting multiple sclerosis: a multicentre, randomised, double-blind, placebo-controlled phase Ilb study. Lancet. 2008:372:1463-72.

17. Bomprezzi R. Dimethyl fumarate in the treatment of relapsing-remitting multiple sclerosis: an overview. Ther Adv Neurol Disord. 2015:8:20-30.

18. Nguyen T, Nioi P, Pickett CB. The Nrf2-antioxidant response element signaling pathway and its activation by oxidative stress. J Biol Chem. 2009:284:13291-5.

19. Di W, Shi X, Lv H, Liu J, Zhang H, Li Z, Fang Y. Activation of the nuclear factor E2-related factor 2/anitioxidant response element alleviates the nitroglycerin-induced hyperalgesia in rats. J Headache Pain. 2016;17:99.

20. Di Clemente L, Coppola G, Magis D, Gerardy PY, Fumal A, De Pasqua V, Di Piero V, Schoenen J. Nitroglycerin sensitises in healthy subjects CNS structures involved in migraine pathophysiology: evidence from a study of nociceptive blink reflexes and visual evoked potentials. Pain. 2009;144:156-61.

21. Ferrari MD, Roon KI, Lipton RB, Goadsby PJ. Oral triptans (serotonin 5-HT(1B/ 1D) agonists) in acute migraine treatment: a meta-analysis of 53 trials. Lancet. 2001:358:1668-75.

22. Bates EA, Nikai T, Brennan KC, Fu YH, Charles AC, Basbaum Al, Ptacek LJ Ahn AH. Sumatriptan alleviates nitroglycerin-induced mechanical and thermal allodynia in mice. Cephalalgia. 2010;30:170-8.

23. Dubey D, Kieseier BC, Hartung HP, Hemmer B, Warnke C, Menge T, MillerLittle WA, Stuve O. Dimethyl fumarate in relapsing-remitting multiple sclerosis: rationale, mechanisms of action, pharmacokinetics, efficacy and safety. Expert Rev Neurother. 2015;15:339-46.

24. Litjens NH, Burggraaf J, van Strijen E, van Gulpen C, Mattie H, Schoemaker $\mathrm{RC}$, van Dissel JT, Thio HB, Nibbering PH. Pharmacokinetics of oral fumarates in healthy subjects. Br J Clin Pharmacol. 2004;58:429-32.

25. Wang ZQ, Porreca F, Cuzzocrea S, Galen K, Lightfoot R, Masini E, Muscoli C, Mollace V, Ndengele M, Ischiropoulos $H$, Salvemini D. A newly identified role for superoxide in inflammatory pain. J Pharmacol Exp Ther. 2004;309:869-78.

26. Fu H, Fang $P$, Zhou HY, Zhou J, Yu XW, Ni M, Zheng JY, Jin Y, Chen JG, Wang F, Hu ZL. Acid-sensing ion channels in trigeminal ganglion neurons innervating the orofacial region contribute to orofacial inflammatory pain. Clin Exp Pharmacol Physiol. 2016:43:193-202.

27. Raboisson P, Dallel R. The orofacial formalin test. Neurosci Biobehav Rev. 2004:28:219-26.

28. Yamamoto T, Nozaki-Taguchi N, Chiba T. Analgesic effect of intrathecally administered orexin-a in the rat formalin test and in the rat hot plate test. Br J Pharmacol. 2002;137:170-6.

29. Sufka KJ, Staszko SM, Johnson AP, Davis ME, Davis RE, Smitherman TA. Clinically relevant behavioral endpoints in a recurrent nitroglycerin migraine model in rats. J Headache Pain. 2016;17:40.

30. Tureyen K, Vemuganti R, Sailor KA, Dempsey RJ. Infarct volume quantification in mouse focal cerebral ischemia: a comparison of triphenyltetrazolium chloride and cresyl violet staining techniques. J Neurosci Methods. 2004;139:203-7.

31. Casili G, Campolo M, Paterniti I, Lanza M, Filippone A, Cuzzocrea S, Esposito E. Dimethyl fumarate attenuates neuroinflammation and neurobehavioral deficits induced by experimental traumatic brain injury. J Neurotrauma. 2018;35:1437-51.

32. Campolo M, Ahmad A, Crupi R, Impellizzeri D, Morabito R, Esposito E, Cuzzocrea S. Combination therapy with melatonin and dexamethasone in a mouse model of traumatic brain injury. J Endocrinol. 2013;217:291-301.

33. Capuano A, De Corato A, Lisi L, Tringali G, Navarra P, Dello Russo C. Proinflammatory-activated trigeminal satellite cells promote neuronal sensitization: relevance for migraine pathology. Mol Pain. 2009;5:43. 
34. Campolo M, Casili G, Biundo F, Crupi R, Cordaro M, Cuzzocrea S, Esposito E. The neuroprotective effect of dimethyl Fumarate in an MPTP-mouse model of Parkinson's disease: involvement of reactive oxygen species/nuclear factor-kappaB/nuclear transcription factor related to NF-E2. Antioxid Redox Signal. 2017;27:453-71.

35. Siracusa R, Paterniti I, Impellizzeri D, Cordaro M, Crupi R, Navarra M, Cuzzocrea S, Esposito E. The Association of Palmitoylethanolamide with Luteolin decreases neuroinflammation and stimulates autophagy in Parkinson's disease model. CNS Neurol Disord Drug Targets. 2015;14:1350-65.

36. Abdallah K, Artola A, Monconduit L, Dallel R, Luccarini P. Bilateral descending hypothalamic projections to the spinal trigeminal nucleus caudalis in rats. PLoS One. 2013;8:e73022.

37. Noseda R, Burstein R. Migraine pathophysiology: anatomy of the trigeminovascular pathway and associated neurological symptoms, cortical spreading depression, sensitization, and modulation of pain. Pain. 2013; 154(Suppl 1S):44-53.

38. Pradhan AA, Smith ML, McGuire B, Tarash I, Evans CJ, Charles A. Characterization of a novel model of chronic migraine. Pain. 2014;155:269-74.

39. Furman JM, Balaban CD, Jacob RG, Marcus DA. Migraine-anxiety related dizziness (MARD): a new disorder? J Neurol Neurosurg Psychiatry. 2005;76:1-8.

40. Minen MT, Begasse De Dhaem O, Kroon Van Diest A, Powers S, Schwedt TJ, Lipton R, Silbersweig D. Migraine and its psychiatric comorbidities. J Neurol Neurosurg Psychiatry. 2016;87:741-9.

41. Wu Y, Hallett M. Photophobia in neurologic disorders. Transl Neurodegener. 2017;6:26.

42. Alp R, Selek S, Alp SI, Taskin A, Kocyigit A. Oxidative and antioxidative balance in patients of migraine. Eur Rev Med Pharmacol Sci. 2010;14:877-82

43. Mark W. Weatherall. The diagnosis and treatment of chronic migraine. Ther Adv Chronic Dis. 2015;6(3):115-123.

44. Lee I, Kim HK, Kim JH, Chung K, Chung JM. The role of reactive oxygen species in capsaicin-induced mechanical hyperalgesia and in the activities of dorsal horn neurons. Pain. 2007:133:9-17.

45. Takano T, Tian GF, Peng W, Lou N, Lovatt D, Hansen AJ, Kasischke KA, Nedergaard M. Cortical spreading depression causes and coincides with tissue hypoxia. Nat Neurosci. 2007;10:754-62.

46. Viggiano A, Viggiano E, Valentino I, Monda M, Viggiano A, De Luca B. Cortical spreading depression affects reactive oxygen species production. Brain Res. 2011:1368:11-8.

47. Halliwell B. Reactive oxygen species and the central nervous system. J Neurochem. 1992:59:1609-23.

48. Tozzi-Ciancarelli MG, De Matteis G, Di Massimo C, Marini C, Ciancarelli I, Carolei A. Oxidative stress and platelet responsiveness in migraine. Cephalalgia. 1997;17:580-4.

49. Bockowski L, Sobaniec W, Kulak W, Smigielska-Kuzia J. Serum and intraerythrocyte antioxidant enzymes and lipid peroxides in children with migraine. Pharmacol Rep. 2008;60:542-8.

50. Tuncel D, Tolun Fl, Gokce M, Imrek S, Ekerbicer H. Oxidative stress in migraine with and without aura. Biol Trace Elem Res. 2008;126:92-7.

51. Lee JM, Johnson JA. An important role of Nrf2-ARE pathway in the cellular defense mechanism. J Biochem Mol Biol. 2004;37:139-43.

52. Sandberg M, Patil J, D'Angelo B, Weber SG, Mallard C. NRF2-regulation in brain health and disease: implication of cerebral inflammation. Neuropharmacology. 2014;79:298-306

53. Traub J, Traffehn S, Ochs J, Hausser-Kinzel S, Stephan S, Scannevin R, Bruck W, Metz I, Weber MS. Dimethyl fumarate impairs differentiated B cells and fosters central nervous system integrity in treatment of multiple sclerosis. Brain Pathol. 2019;29(5):640-57.

54. Ellrichmann G, Petrasch-Parwez E, Lee DH, Reick C, Arning L, Saft C, Gold R, Linker RA. Efficacy of fumaric acid esters in the R6/2 and YAC128 models of Huntington's disease. PLoS One. 2011;6:e16172.

55. Yao Y, Miao W, Liu Z, Han W, Shi K, Shen Y, Li H, Liu Q, Fu Y, Huang D, Shi FD. Dimethyl fumarate and monomethyl fumarate promote post-ischemic recovery in mice. Transl Stroke Res. 2016;7:535-47.

56. Hiruma-Lima CA, Gracioso JS, Bighetti EJ, Germonsen Robineou L, Souza Brito AR. The juice of fresh leaves of Boerhaavia diffusa L. (Nyctaginaceae) markedly reduces pain in mice. J Ethnopharmacol. 2000;71:267-74.

57. Oh K, Cho SJ, Chung YK, Kim JM, Chu MK. Erratum to: combination of anxiety and depression is associated with an increased headache frequency in migraineurs: a population-based study. BMC Neurol. 2016;16:51.

58. Kawasaki A, Purvin VA. Photophobia as the presenting visual symptom of chiasmal compression. J Neuroophthalmol. 2002;22:3-8.
59. Basbaum Al, Bautista DM, Scherrer G, Julius D. Cellular and molecular mechanisms of pain. Cell. 2009:139:267-84.

60. Robert C, Bourgeais L, Arreto CD, Condes-Lara M, Noseda R, Jay T, Villanueva L. Paraventricular hypothalamic regulation of trigeminovascular mechanisms involved in headaches. J Neurosci. 2013;33:8827-40.

61. Burstein R, Jakubowski M, Garcia-Nicas E, Kainz V, Bajwa Z, Hargreaves R, Becerra $L$, Borsook D. Thalamic sensitization transforms localized pain into widespread allodynia. Ann Neurol. 2010;68:81-91.

62. Burstein R, Yamamura H, Malick A, Strassman AM. Chemical stimulation of the intracranial dura induces enhanced responses to facial stimulation in brain stem trigeminal neurons. J Neurophysiol. 1998:79:964-82.

63. Pardutz A, Multon S, Malgrange B, Parducz A, Vecsei L, Schoenen J. Effect of systemic nitroglycerin on CGRP and 5-HT afferents to rat caudal spinal trigeminal nucleus and its modulation by estrogen. Eur J Neurosci. 2002;15:1803-9.

64. Li Y, Zhang Q, Qi D, Zhang L, Yi L, Li Q, Zhang Z. Valproate ameliorates nitroglycerin-induced migraine in trigeminal nucleus caudalis in rats through inhibition of NF-small ka, CyrillicB. J Headache Pain. 2016;17:49.

65. Tassorelli C, Greco R, Morazzoni P, Riva A, Sandrini G, Nappi G. Parthenolide is the component of tanacetum parthenium that inhibits nitroglycerininduced Fos activation: studies in an animal model of migraine. Cephalalgia. 2005;25:612-21.

66. Reuter U, Chiarugi A, Bolay H, Moskowitz MA. Nuclear factor-kappaB as a molecular target for migraine therapy. Ann Neurol. 2002;51:507-16.

67. Perry CJ, Blake P, Buettner C, Papavassiliou E, Schain AJ, Bhasin MK, Burstein R. Upregulation of inflammatory gene transcripts in periosteum of chronic migraineurs: implications for extracranial origin of headache. Ann Neurol. 2016:79:1000-13.

68. Conti P, D'Ovidio C, Conti C, Gallenga CE, Lauritano D, Caraffa A, Kritas SK, Ronconi G. Progression in migraine: role of mast cells and pro-inflammatory and anti-inflammatory cytokines. Eur J Pharmacol. 2019;844:87-94.

69. Singh N, Saha L, Kumari P, Singh J, Bhatia A, Banerjee D, Chakrabarti A. Effect of dimethyl fumarate on neuroinflammation and apoptosis in pentylenetetrazol kindling model in rats. Brain Res Bull. 2019;144:233-45.

70. Kobayashi EH, Suzuki T, Funayama R, Nagashima T, Hayashi M, Sekine H, Tanaka N, Moriguchi T, Motohashi H, Nakayama K, Yamamoto M. Nrf2 suppresses macrophage inflammatory response by blocking proinflammatory cytokine transcription. Nat Commun. 2016:7:11624.

71. Kaspar JW, Niture SK, Jaiswal AK. Nrf2:INrf2 (Keap1) signaling in oxidative stress. Free Radic Biol Med. 2009;47:1304-9.

72. Hammer A, Waschbisch A, Kuhbandner K, Bayas A, Lee DH, Duscha A, Haghikia A, Gold R, Linker RA. The NRF2 pathway as potential biomarker for dimethyl fumarate treatment in multiple sclerosis. Ann Clin Transl Neurol. 2018;5:668-76

\section{Publisher's Note}

Springer Nature remains neutral with regard to jurisdictional claims in published maps and institutional affiliations.

Ready to submit your research? Choose BMC and benefit from:

- fast, convenient online submission

- thorough peer review by experienced researchers in your field

- rapid publication on acceptance

- support for research data, including large and complex data types

- gold Open Access which fosters wider collaboration and increased citations

- maximum visibility for your research: over $100 \mathrm{M}$ website views per year

At BMC, research is always in progress.

Learn more biomedcentral.com/submissions 